\title{
Corrigendum
}

\section{What's on the menu? A review of the energy and nutritional content of US chain restaurant menus - Corrigendum}

\author{
Helen W Wu and Roland Sturm
}

First published online 9 August 2012

doi:10.1017/S136898001200122X, Published online by Cambridge University Press 11 May 2012

In the Design section of the Abstract, the sentence:

Descriptive statistics and multivariate regression analysis of the energy, total fat, saturated fat, trans fat, sodium, carbohydrate and protein levels of 28433 regular and 1833 children's menu items.

should read as follows:

Descriptive statistics and multivariate regression analysis of the energy, total fat, saturated fat, trans fat, sodium, carbohydrate and protein levels of 29531 regular and 1392 children's menu items.

\section{Reference}

Wu HW \& Sturm R (2012) What's on the menu? A review of the energy and nutritional content of US chain restaurant menus. Public Health Nutrition, published online 11 May 2012, doi:10.1017/\$136898001200122X. 